\title{
Politically correct names given to flu viruses
}

Names of flu viruses appearing in the scientific literature have undergone something of a mutation this year. The group of $\mathrm{H} 5 \mathrm{~N} 1$ avian flu viruses, once known as 'Fujian-like', has morphed into 'Clade 2.3.4'. And its 'Qinghailike' cousin is now called 'Clade 2.2'. They are part of a complete revision of $\mathrm{H} 5 \mathrm{~N} 1$ nomenclature recommended by the World Health Organization (WHO).

The system is now more politically correct. It avoids the "stigmatizing labelling of clades by geographical reference", according to the WHO. In 2006, when scientists assigned the name 'Fujian-like virus' to a vaccine-resistant strain of H5N1 that spread across Asia, China objected strongly to the name. Government officials argued that the southeastern Chinese province of Fujian was tainted by association as the virus spread.

But a WHO official told Nature that discussions for a revised nomenclature were underway before the spat, and that the "impetus was scientific". "We recognized that naming based on geography was probably not a good idea for other reasons," she says.

Flu experts say that the new naming recommendations, which have been posted on the WHO website and have been submitted for publication in the journal Emerging Infectious Diseases, make a lot of sense. They replace an ad-hoc system, in which researchers would invent their own names for newly isolated groups, with a systematic one in which names have greater biological relevance.

$\mathrm{H} 5 \mathrm{~N} 1$ viruses are classified on the basis of their

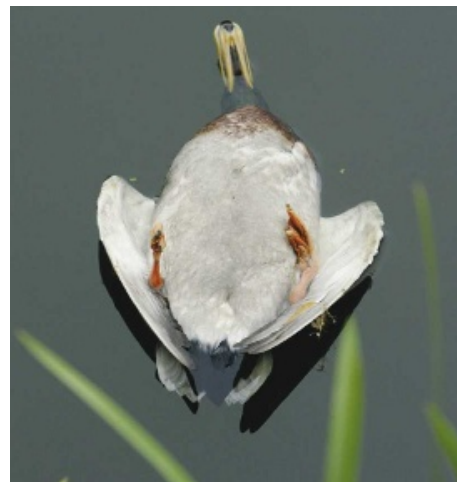

Bird flu knows no national borders. causing outbreaks in more than 60 countries from Azerbaijan to Nigeria and Pakistan.

"I find the geographical naming system rather confusing and unspecific; this more precise numbering system is far more rigorous," says Edward Holmes, a flu genomicist at Pennsylvania State University in University Park. The new system does not affect the naming of individual H5N1 virus sequences - held in the GenBank database - that make up such clades. These will continue to display geographic and species data on the sample. Geographic information is relevant, says the WHO official, because it locates the sample's place of origin.

But experts say that the location data in GenBank flu names is woefully inadequate for serious spatial science, such as analysing the spread of virus genotypes or how spread relates to other spatial data on land use, climate and trade. "There's nothing more frustrating and useless to a phylogeographer than a perfectly sequenced isolate labelled 'China,'” says Rob Wallace, an evolutionary ecologist at the University of California, Irvine. "With Global Positioning System (GPS) coordinates and fine enough sampling we would really be able to tease out how the virus evolves and spreads across farms and wetlands."

Indeed, not one H5N1 sequence in GenBank currently contains GPS coordisubmitting sequences have no use for such data. "Given the importance of avian flu, I've been amazed to find out how difficult it has been to get information on the geographical distribution of essential variables," says ecologist Marius Gilbert, of haemagglutinin genetic sequence into ten phylogenetic clades - distinct branches of the virus's family tree - and the new system names the viral subgroups according to their position in the tree. It aims to be more logical. For example, Clade 2.3.4 viruses are not restricted to Fuijan province, they have caused cases in humans in China, Laos, Myanmar and Vietnam. Clade 2.1 viruses dominate in poultry and humans in Indonesia, for example, whereas Clade 2.2 viruses have the largest geographical spread, the Free University of Brussels. The WHO official agrees that the current sequence-naming system is not as useful as GPS coordinates, but says that "the WHO doesn't see its business as making that sort of requirement".

GenBank only introduced fields for latitude and longitude in submitted entries in 2005 and few scientists have so far used them, except in spatially aware fields, such as forest entomology and biodiversity.

Declan Butler
SHOWBIZ NEWS

Formulaic pop

R\&B diva Mariah

Carey has somewhat surprisingly titled her latest album $\mathrm{E}=\mathrm{MC}^{2}$, not as a homage to the main man Einstein, but because it's allegedly short for "Emancipation equals Mariah Carey times two". Somebody please teach her some maths before she releases more music.

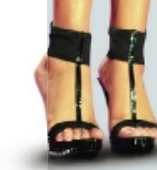

ON THE RECORD ccontrary to recent press reports, NASA offices involved in near-Earth object research were not contacted and have had no correspondence with a young German student.》

The agency denies accepting help from 13-year-old Nico Marquardt in working out how likely we are to be hit by the asteroid Apophis.

\section{WORDWATCH}

\section{Nerdic}

Also known as 'geek speak', it is the fastest-growing 'language' in the world, adding about 100 new terms every year, including the verb 'to Google'.

\section{SCORECARD}

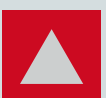
Moon crops European Space Agency scientists find that plants can grow, without needing extra food, in crushed-up rock very like the lunar surface.

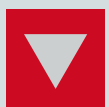
Space tourism Just as everyone else jumps on the spacetourism bandwagon, the world's top space-travel company, the Russian government, announces that it may stop selling space voyages in 2010 , to save more seats for cosmonauts. 